ORIGINAL ARTICLE

\title{
Exposure to welding fumes is associated with acute systemic inflammatory responses
}

\author{
J Y Kim, J-C Chen, P D Boyce, D C Christiani
}

Occup Environ Med 2005;62:157-163. doi: 10.1136/oem.2004.014795

See end of article for authors' affiliations ......................

Correspondence to: Prof. D C Christiani Harvard School of Public Health, Occupational Health Program, Building I, Room 1402, 665 Huntington Avenue, Boston, MA 02115, USA; dchristi@hsph.harvard.edu

Accepted 19 October 2004

\begin{abstract}
Aims: To investigate the acute systemic inflammatory response to welding fume exposure. Methods: Twenty four welders (42\% smokers) and 13 non-exposed controls (23\% smokers) were monitored at a welding school. Exposure to fine particulate matter $\left(\mathrm{PM}_{2.5}\right)$ was assessed using cyclone samplers. Markers of systemic inflammation, including C-reactive protein (CRP), fibrinogen, and white blood cell (WBC) levels, were determined in peripheral blood samples collected at baseline and after 5.3 (SD 1.0) hours of exposure.

Results: The median $\mathrm{PM}_{2.5}$ concentration for welders was $1.66 \mathrm{mg} / \mathrm{m}^{3}$, which was significantly greater than that for controls $\left(0.04 \mathrm{mg} / \mathrm{m}^{3}\right)$. Compared to non-smokers, smokers had a significantly higher baseline WBC count, but comparable levels of CRP and fibrinogen. In non-smokers, welding fume exposure was associated with a significant increase in WBC and neutrophil counts immediately following exposure $\left(+0.8 \times 10^{3} / \mu \mathrm{l}, 95 \% \mathrm{Cl} 0.1\right.$ to 1.6 , and $+1.0 \times 10^{3} / \mu \mathrm{l}, 95 \% \mathrm{Cl} 0.4$ to 1.7 , respectively). A significant decrease in fibrinogen levels was observed in non-smokers $(-32 \mathrm{mg} / \mathrm{dl}, 95 \% \mathrm{Cl}-63$ to -1$)$. No significant changes in WBC, neutrophil, and fibrinogen levels were found in smokers. Sixteen hours after welding exposure, CRP levels were found to be significantly increased in both non-smokers and smokers $(0.90 \mathrm{mg} / \mathrm{I}, 95 \% \mathrm{Cl} 0.17$ to 1.64$)$. $\mathrm{PM}_{2.5}$ concentrations were found to be significantly associated with absolute neutrophil counts in non-smokers, and CRP levels in both non-smokers and smokers.

Conclusions: High levels of welding fume exposure induce acute systemic inflammation in a relatively young, healthy working population. These results also suggest that smoking may modify the effect of welding fume exposure on specific inflammatory markers.
\end{abstract}

$\mathrm{T}$ he process of welding involves joining metal parts by heating the pieces to melting temperatures. ${ }^{1}$ Welding generates high levels of metal fume, which is comprised primarily of fine and ultrafine particles. ${ }^{2}$ Epidemiological studies have shown that exposure to welding fumes is associated with metal fume fever ${ }^{3}$ and increased respiratory symptoms. ${ }^{35}$ In addition, welders experience an increased prevalence of inflammatory lung diseases such as asthma and chronic bronchitis. ${ }^{6-9}$ Chronic exposure to welding fumes also is associated with a significant reduction in lung function; ${ }^{810}$ however, this association often is observed only in smoking welders, suggesting a possible interaction between welding fume and tobacco smoke on pulmonary responses.

In addition to causing adverse pulmonary effects, there is growing evidence that welding fume exposure also may be associated with increased cardiovascular events. Several studies have found that welders experience increased mortality from ischaemic heart disease. ${ }^{11-13}$ The observed increase in cardiovascular mortality most likely is not attributable solely to smoking. In a recent Swedish census, Sjögren and colleagues found that welders had a $10 \%$ excess risk in mortality from ischaemic heart disease compared to the general population, even after adjusting for smoking. ${ }^{13}$ Although the exact mechanisms are unknown, systemic inflammation resulting from occupational exposure to welding fume may be partially responsible for the increased cardiovascular risk in welders.

$\mathrm{C}$-reactive protein (CRP), and to a lesser extent, fibrinogen and white blood cells (WBC) have been shown to be highly predictive of coronary heart disease. ${ }^{14-18} \mathrm{WBC}$, in particular neutrophils, are the primary acute inflammatory cells. The acute phase proteins CRP and fibrinogen also are sensitive, non-specific markers of inflammation. ${ }^{19} 20 \mathrm{WBC}, \mathrm{CRP}$, and fibrinogen levels have been utilised in numerous clinical and toxicological studies of inflammation, as well as in epidemiological studies investigating the association between particulate air pollution and acute systemic inflammation. ${ }^{21-23}$

In this study, we investigated the systemic inflammatory response to welding fume exposure. Blood samples were collected from welders and non-welding controls before and after their workshift. The inflammatory response attributable to welding exposure was determined by comparing CRP, fibrinogen, and WBC levels across the workshift. Data were further stratified by smoking status to determine whether smoking modified the effect of welding fume on the systemic inflammatory markers. Previous epidemiological studies have shown that cigarette smoking significantly affects CRP, fibrinogen, and WBC levels. ${ }^{24-26}$ We hypothesised that welding fume exposure would be associated with systemic inflammation, indicated by increased CRP, fibrinogen, and WBC levels. We further hypothesised that smoking status would significantly modify the association between welding fume and the various systemic inflammatory markers.

\section{MATERIALS AND METHODS}

\section{Study population}

The study was approved by the Institutional Review Board of the Harvard School of Public Health (Boston, MA, USA). Written informed consent was obtained from each subject. The study population consisted of 37 active and inactive boilermakers. Subjects were recruited and monitored at an

Abbreviations: $95 \% \mathrm{Cl}, 95 \%$ confidence interval; ATS, American Thoracic Society; CRP, C-reactive protein; $\mathrm{PM}_{2.5}$, particulate matter with an aerodynamic mass median diameter $\leqslant 2.5 \mu \mathrm{m} ; \mathrm{PM}_{10}$, particulate matter with an aerodynamic mass median diameter $\leqslant 10 \mu \mathrm{m} ; \mathrm{RBC}$, red blood cell; SD, standard deviation; SEM, standard error of the mean; WBC, white blood cell 
apprentice welding school (Quincy, MA, USA) over three sampling periods, January/February 2003, June 2003, and January/February 2004. Sixteen of the 37 subjects were monitored more than once during the three sampling periods. A modified American Thoracic Society (ATS) questionnaire was used to collect information on medical history, current cardiopulmonary symptoms, smoking history, and occupational history of the subjects.

Twenty four subjects were exposed to metal fume and airborne fine particulate matter from shielded metal arc welding, gas tungsten arc welding (TIG welding), plasma arc cutting, and grinding. The most commonly used base metal was carbon steel. These 24 subjects with high levels of exposure to metal fume and fine particles were categorised as welders. Thirteen additional subjects served as controls, exposed primarily to background levels of particulate matter while performing bookwork and office tasks at the welding school.

\section{Exposure assessment}

Personal particle samplers were placed on the lapels of the subjects during their workday to monitor exposure to particles with an aerodynamic mass median diameter $\leqslant 2.5 \mu \mathrm{m}$ $\left(\mathrm{PM}_{2.5}\right)$. The KTL cyclone (GK2.05SH, BGI Incorporated, Waltham, MA, USA) with a $50 \%$ aerodynamic diameter cutpoint of $2.5 \mu \mathrm{m}$ was used in line with a Vortex Timer 2 personal sampling pump (Casella USA, Amherst, NH, USA) calibrated at a flow rate of $3.5 \mathrm{l} / \mathrm{min}$. The air sample was collected on a $37 \mathrm{~mm}$ polytetrafluoroethylene membrane filter (Gelman Laboratories, Ann Arbor, MI, USA) encased in a cassette and placed downstream of the cyclone. The filters were weighed before and after sampling on a MT5 microbalance from Mettler-Toledo Incorporated (Columbus, $\mathrm{OH}$, USA) after equilibrating for a minimum of 24 hours in a temperature and humidity controlled room. The mass collected on the filter was divided by the air volume sampled to calculate the gravimetric $\mathrm{PM}_{2.5}$ concentration.

\section{Systemic inflammatory marker measurements}

Venous blood samples were collected before work (baseline) and immediately after the end of the workday (six hours post-baseline). On a subset of subjects $(n=13)$, blood samples were also collected 24 hours after the baseline measurement. Blood samples were sent to Path Lab Incorporated (Portsmouth, NH, USA) for analysis. The Path Lab testing facility is in accordance with the Clinical Laboratory Improvement Amendments of 1988. Blood samples were analysed for CRP, fibrinogen, and total WBC count with differential. Quantitative determination of CRP in serum was performed with a Boehringer Mannheim/Hitachi 911 analyser (Roche Diagnostics Corporation, Indianapolis, IN, USA) using the latex particle enhanced immunoturbidimetric assay. The fibrinogen concentration in plasma was determined quantitatively with the Sysmex CA5000 coagulation analyser (Sysmex America, Incorporated, Mundelein, IL, USA) using the Clauss clotting method. ${ }^{27}$ The total WBC count was performed with an ADVIA 120 automatic cell counter (Bayer Diagnostics, Tarrytown, NY, USA) after haemolysing the red blood cells (RBC). The differential WBC count was performed with the ADVIA 120 analyser after differential cellular staining using the peroxidase method.

\section{Urine analysis for cotinine}

Urine samples were collected in sterile $120 \mathrm{ml}$ containers before and after the workday, then aliquoted into $15 \mathrm{ml}$ polypropylene tubes. Samples were sent to Path Lab Incorporated (Portsmouth, NH, USA) for urinary cotinine analysis. The presence of cotinine in urine was detected using an immunoassay procedure on an Olympus AU800 chemical analyser.

\section{Statistical analysis}

Statistical analyses were performed using SAS version 6.12 (SAS Institute Incorporated, Cary, NC, USA). Exposure status was dichotomised as non-exposed controls and welders. Study population characteristics between controls and welders were compared using two-sample $t$ tests, Wilcoxon rank sum tests with exact $\mathrm{p}$ values, and Fisher's exact test. The mean (standard deviation, SD) and median (25th-75th centile) values of the $\mathrm{PM}_{2.5}$ concentrations were determined for controls and welders. Two-sample $t$ tests and Wilcoxon rank sum tests with exact $p$ values were performed to compare the $\mathrm{PM}_{2.5}$ concentrations in controls and welders, and also in smokers and non-smokers. Dichotomised smoking status (yes/no) was confirmed by the presence of cotinine in the urine samples.

A total of 127 blood samples were collected from 37 subjects. Subjects provided two to three blood samples each time they participated, all at baseline and six hours postbaseline, and a subset at 24 hours post-baseline. In addition, 12 of the 37 subjects participated during two sampling periods and four participated in all three sampling periods. Baseline mean (standard error of the mean, SEM) levels of CRP, fibrinogen, WBC, and neutrophils were determined by exposure status and smoking status. To account for the repeated measurements, linear mixed models were used to investigate the effect of welding fume exposure on the systemic inflammatory markers. A generalised autoregressive covariance structure was used to account for the exponential decay of the correlation function as the interval between the measurements increased. ${ }^{28}$ Restricted maximum likelihood was used to estimate the covariance parameters. The effect of age on the baseline levels of the systemic inflammatory markers also was investigated. The distribution of residuals was examined using the Shapiro-Wilks test for normality and normal probability plots. Although the Shapiro-Wilks tests indicated that the residuals from some of the models might not be normally distributed $(\mathrm{p}<0.05)$, the lack of significant curvature in the normal probability plots for all the models suggested that it was reasonable to assume that the random errors were approximately normally distributed. Therefore, for ease of interpretation of the results, the outcome variables were not transformed.

The following mixed effect model was constructed to examine the main effect of welding fume exposure on the measured change in inflammatory markers, adjusting for potential confounding by age, smoking, and time effects:

- Model 1: ( $\Delta$ systemic inflammatory marker $)_{i j}=\beta_{0}+$ $\beta_{1}(\text { age }-37 \mathrm{y})_{i}+\beta_{2}$ ( smoking status $)_{i}+\beta_{3}(\text { sampling time })_{i j}$ $+\beta_{4}(\text { exposure status })_{i}+\beta_{5}\left[(\text { exposure status })_{i} \times(\right.$ sampling time $\left.)_{i j}\right]+e_{i j}$

where $\beta_{4}$ indicates the effect of welding fume exposure at 6 hours and $\beta_{4}+\beta_{5}$ represents the welding fume exposure at 24 hours, after adjusting for the effects of age $\left(\beta_{1}\right)$ and smoking $\left(\beta_{2}\right)$.

To further examine whether the effect of welding fume exposure depends on smoking status, the following mixed effect model with interaction terms between the main effect and smoking status was constructed:

- Model 2: ( $\Delta$ systemic inflammatory marker $)_{i j}=\beta_{0}+$ $\beta_{1}(\text { age }-37 y)_{i}+\beta_{2}$ (smoking status $)_{i}+\beta_{3}(\text { sampling time })_{i j}$ $+\beta_{4}$ (exposure status $)_{i}+\beta_{5}\left[(\text { exposure status })_{i} \times(\right.$ sampling time $\left.)_{i j}\right]+\beta_{6}\left[(\text { exposure status })_{i} \times(\text { smoking status })_{i}\right]+$ $\beta_{7}\left[(\text { exposure status })_{i} \times(\text { smoking status })_{i} \times(\right.$ sampling time $\left.)_{i j}\right]+e_{i j}$ 

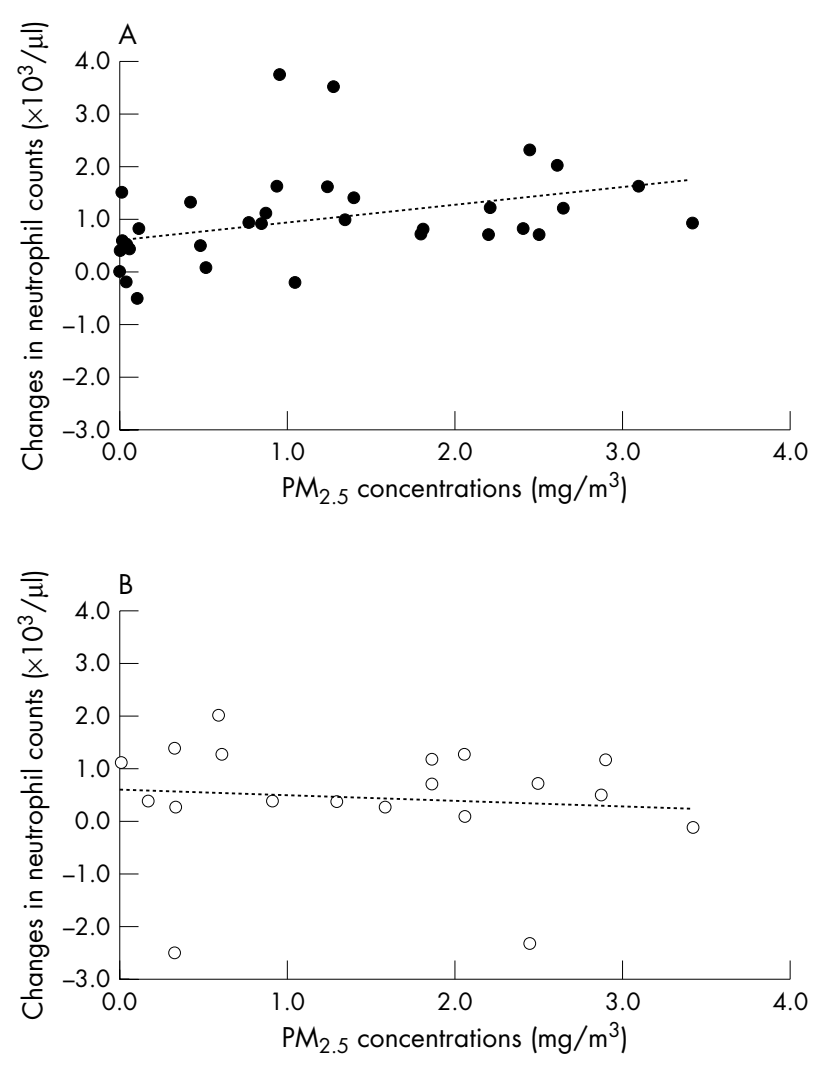

Figure 1 Scatterplot of $\mathrm{PM}_{2.5}$ concentrations and baseline to 6 hours post-baseline changes in neutrophil counts; (A) non-smokers, (B) smokers.

where $\beta_{4}$ and $\beta_{4}+\beta_{5}$ now indicate the effect of welding fume exposure at 6 hours and 24 hours among non-smokers, after adjusting for the effects of age $\left(\beta_{1}\right)$ and smoking $\left(\beta_{2}\right) \cdot \beta_{4}+\beta_{6}$ and $\beta_{4}+\beta_{5}+\beta_{6}+\beta_{7}$ represent the effect of welding fume exposure at 6 hours and 24 hours among smokers. These two models were compared using the likelihood ratio test.

Similar models were used to investigate the linear exposure-response association between $\mathrm{PM}_{2.5}$ concentrations, indicated as a continuous variable, and levels of systemic inflammatory markers. The linear exposureresponse association was examined based on scatterplots of data stratified by smoking status indicating an approximately linear relation between $\mathrm{PM}_{2.5}$ concentrations and changes in systemic inflammatory markers. Figure 1, for example, depicts the relation between $\mathrm{PM}_{2.5}$ concentrations and changes in neutrophil counts 6 hours post-baseline in nonsmokers and smokers. The level of significance for all analyses was set at 0.05 .

\section{RESULTS}

\section{Study population characteristics}

Table 1 presents the study population demographic data. The study population included 37 men, of which 24 were welders and 13 served as controls. Their ages ranged from 19 to 61 years, with a mean of 41.5 years (SD 15.9) for controls and 35.0 years (SD 8.0) for welders. The controls had 5.0 years (median) of boilermaking experience, while the welders had 3.0 years (median) of experience. The mean age and median years of boilermaking were not significantly different in controls and welders $(p \geqslant 0.1)$. Three of the 13 controls $(23 \%)$ and 10 of the 24 welders $(42 \%)$ were current cigarette smokers. The percentage of smokers in each group was not significantly different $(p=0.3)$. In general, the study population consisted of relatively young, healthy workers, with few having underlying respiratory or cardiopulmonary diseases.

\section{Particle exposure assessment}

Table 1 also shows the personal $\mathrm{PM}_{2.5}$ exposure data. Particle samples were collected from all controls and welders during the workday. Four of the 13 controls and 12 of the 24 welders were monitored on additional sampling days. The subjects, on average, worked for six hours at the welding school. Personal particulate matter samples were collected for a mean sampling time of 5.1 hours (SD 1.1) in controls and 5.3 hours (SD 0.9) in welders. The median $\mathrm{PM}_{2.5}$ concentration in controls was $0.04 \mathrm{mg} / \mathrm{m}^{3}$, with 25 th-75th centile values of $0.02-0.11 \mathrm{mg} / \mathrm{m}^{3}$. In welders, the median $\mathrm{PM}_{2.5}$ concentration was $1.69 \mathrm{mg} / \mathrm{m}^{3}$, with 25 th-75th centile values of $0.89-2.44 \mathrm{mg} / \mathrm{m}^{3}$. The median $\mathrm{PM}_{2.5}$ concentrations were significantly different between controls and welders $(\mathrm{p}<0.001)$.

\section{Baseline measurements of systemic inflammatory markers}

Table 2 shows the baseline mean (SEM) levels of the systemic inflammatory markers. Age was shown to be a significant positive predictor of CRP and fibrinogen $(p \leqslant 0.02)$, therefore all analyses were adjusted for centred age. Controls and welders were not found to have significantly different age adjusted mean baseline levels of systemic inflammatory markers $(\mathrm{p}>0.05)$. In addition, the mean baseline CRP and fibrinogen levels were not significantly different in nonsmokers and smokers $(p \geqslant 0.2)$.

Smoking status was shown to affect mean baseline WBC counts $(\mathrm{p}<0.001)$. The mean baseline WBC count was $2.1 \times 10^{3} / \mu \mathrm{l}(95 \%$ CI 1.2 to 3.1$)$ greater in smokers compared to non-smokers. Similarly, smokers were found to have significantly greater baseline neutrophil counts compared to non-smokers $(p<0.001)$. The mean baseline neutrophil count in smokers was higher by $1.7 \times 10^{3} / \mu \mathrm{l}(95 \%$ CI 0.9 to 2.4) than in non-smokers. The mean percent neutrophils were also significantly different in non-smokers and smokers $(\mathrm{p}=0.05)$.

Prior to participating in this study, the amount of time that subjects had away from boilermaking work ranged from zero days to several years. Analyses indicated that there were no significant differences in the baseline levels of any of the systemic inflammatory markers between subjects who had worked the previous day and those that did not $(\mathrm{p} \geqslant 0.3)$.

\section{Changes in systemic inflammatory marker levels following welding fume exposure}

Table 3 shows the mean effects (95\% CI) of welding fume exposure on levels of systemic inflammatory markers across the workday. The results for the crude models, and age and smoking status adjusted models were similar. In the adjusted models, welding fume exposure resulted in a significant increase in WBC and neutrophil counts $(p \leqslant 0.05)$, in addition to a marginally significant increase in percent neutrophils $(p=0.06)$. In addition, welding fume exposure was associated with a marginally significant decrease in fibrinogen levels $(p=0.08)$.

The age and smoking status adjusted models were compared to the adjusted models with interaction terms for smoking status. The likelihood ratio test indicated that for fibrinogen, and absolute and relative neutrophils, the models with the smoking interaction terms were a better fit for the dataset $(p<0.02)$. For the WBC model, the likelihood ratio test was marginally significant $(p=0.08)$. The significant 


\begin{tabular}{|c|c|c|c|}
\hline & Controls $(n=13)$ & Welders $(n=24)$ & $\mathrm{p}$ value \\
\hline Number (\%) of current smokers & $3(23 \%)$ & $10(42 \%)$ & 0.3 \\
\hline \multicolumn{4}{|l|}{ Age, years } \\
\hline Mean (SD) & $41.5(15.9)$ & $35.0(8.0)$ & 0.2 \\
\hline Range & $19-61$ & $22-50$ & \\
\hline \multicolumn{4}{|l|}{ Years as boilermaker } \\
\hline Median & 5.0 & 3.0 & 0.1 \\
\hline Range & $1.5-35$ & $1-30$ & \\
\hline Number of exposure samples & $17^{*}$ & $40 \dagger$ & \\
\hline \multicolumn{4}{|l|}{ Sampling time, hours } \\
\hline Mean (SD) & $5.1(1.1)$ & $5.3(0.9)$ & 0.5 \\
\hline \multicolumn{4}{|l|}{$\mathrm{PM}_{2.5}$ concentration, $\mathrm{mg} / \mathrm{m}^{3}$} \\
\hline Mean (SD) & $0.10(0.17)$ & $1.66(0.91)$ & $<0.001$ \\
\hline Median & 0.04 & 1.69 & $<0.001$ \\
\hline 25 th-75th centile & $0.02-0.11$ & $0.89-2.44$ & \\
\hline
\end{tabular}

*Four controls were monitored during two sampling periods. tEight welders were monitored during two sampling periods and four were monitored over three sampling periods.

likelihood ratio test results suggested the presence of effect modification by smoking status.

In smokers, there were no significant changes in any of the systemic inflammatory marker levels immediately following welding fume exposure $(p \geqslant 0.5)$. In contrast, significant changes in WBC counts, and absolute and relative neutrophils were found in non-smokers $(p<0.03)$. Welding fume exposure was associated with an increase of $0.8 \times 10^{3} / \mu \mathrm{l}(95 \%$ CI 0.1 to 1.6$)$ in WBC counts and an increase of $1.0 \times 10^{3} / \mu \mathrm{l}$ (95\% CI 0.4 to 1.7 ) in neutrophil counts. In addition, a significant decrease in fibrinogen levels was observed in nonsmokers $(-32 \mathrm{mg} / \mathrm{dl}, 95 \% \mathrm{CI}-63$ to -1$)$. CRP levels did not change significantly across the workday in non-smokers $(\mathrm{p}=0.4)$.

Blood samples also were collected 24 hours post-baseline, 16 hours after the welding exposure. Table 4 shows the mean effects (95\% CI) of welding fume exposure on levels of systemic inflammatory markers 24 hours after baseline. In both the crude and adjusted models, only CRP levels were significantly associated with welding fume exposure on the previous day $(\mathrm{p}<0.02)$. Exposure to welding fume was associated with an increase in CRP levels by $0.90 \mathrm{mg} / \mathrm{l}$ (95\% CI 0.17 to 1.64), after adjusting for age and smoking status. The interaction term for smoking status was not found to be statistically significant for any of the systemic inflammatory markers, suggesting a lack of effect modification by smoking status 16 hours after exposure $(\mathrm{p}>0.2)$.

\section{Association between $\mathrm{PM}_{2.5}$ exposure and systemic inflammatory marker levels}

Table 5 presents the mean effects (95\% CI) of $\mathrm{PM}_{2.5}$ exposure on levels of systemic inflammatory markers immediately after six hours of exposure. No significant exposure-response relations were observed between $\mathrm{PM}_{2.5}$ concentrations and systemic inflammatory markers in the crude and adjusted models. However, the adjusted models with the smoking interaction terms indicated a statistically significant exposureresponse association between $\mathrm{PM}_{2.5}$ concentrations and neutrophil counts in non-smokers $(\mathrm{p}=0.04)$. With each $1 \mathrm{mg} / \mathrm{m}^{3}$ increase in $\mathrm{PM}_{2.5}$ exposure, absolute neutrophil counts increased by $0.3 \times 10^{3} / \mu \mathrm{l}(95 \%$ CI 0.02 to 0.6$)$ in non-smokers. Similarly, a marginally significant exposure-response association was found between $\mathrm{PM}_{2.5}$ concentrations and WBC counts in non-smokers $(\mathrm{p}=0.09)$. Among non-smokers, each $1 \mathrm{mg} / \mathrm{m}^{3}$ of $\mathrm{PM}_{2.5}$ exposure was associated with a $0.3 \times 10^{3} / \mu \mathrm{l}(95 \% \mathrm{CI}$ -0.05 to 0.7 ) increase in WBC counts.

The association between systemic inflammatory markers and occupational $\mathrm{PM}_{2.5}$ exposure from the previous day was also investigated. Table 6 shows the mean effects (95\% CI) of $\mathrm{PM}_{2.5}$ exposure on levels of systemic inflammatory markers 16 hours after exposure. In both the crude and adjusted models, only CRP was associated significantly with the $\mathrm{PM}_{2.5}$ exposure from the previous day. In the adjusted model, each $1 \mathrm{mg} / \mathrm{m}^{3}$ increase in $\mathrm{PM}_{2.5}$ exposure the previous day was associated with a $0.78 \mathrm{mg} / \mathrm{l}(95 \%$ CI 0.35 to 1.22 ) increase in CRP levels. Smoking status was not found to affect

Table 2 Comparison of mean (SEM)* levels of systemic inflammatory markers at baseline, stratified by exposure and smoking status

\begin{tabular}{|c|c|c|c|c|c|}
\hline \multirow{6}{*}{$\begin{array}{l}\text { Exposure status } \\
\text { C-reactive protein, } \mathrm{mg} / \mathrm{l} \\
\text { Fibrinogen, } \mathrm{mg} / \mathrm{dl} \\
\text { White blood cells, } \times 10^{3} / \mu \mathrm{l} \\
\text { Absolute neutrophils, } \times 10^{3} / \mu \mathrm{l} \\
\text { Relative neutrophils, } \%\end{array}$} & \multicolumn{2}{|c|}{ Controls $(n=13)$} & \multicolumn{2}{|c|}{ Welders ( $n=24$ ) } & \multirow{2}{*}{$\begin{array}{l}\text { P value } \\
0.4\end{array}$} \\
\hline & 2.79 & $(0.60)$ & 2.13 & $(0.38)$ & \\
\hline & 281 & (17) & 286 & (11) & 0.8 \\
\hline & 6.3 & $(0.5)$ & 7.4 & $(0.3)$ & 0.07 \\
\hline & 3.8 & $(0.4)$ & 4.5 & $(0.2)$ & 0.1 \\
\hline & 58 & (2) & 59 & $(2)$ & 0.7 \\
\hline Smoking status & \multicolumn{2}{|c|}{ Non-smokers $(n=13)$} & \multicolumn{2}{|c|}{ Smokers $(n=24)$} & p value \\
\hline C-reactive protein, $\mathrm{mg} / \mathrm{l}$ & 2.47 & $(0.40)$ & 2.07 & $(0.55)$ & 0.6 \\
\hline Fibrinogen, $\mathrm{mg} / \mathrm{dl}$ & 276 & (11) & 300 & (15) & 0.2 \\
\hline White blood cells, $\times 10^{3} / \mu \mathrm{l}$ & 6.3 & (0.3) & 8.5 & $(0.4)$ & $<0.001$ \\
\hline Absolute neutrophils, $\times 10^{3} / \mu \mathrm{l}$ & 3.7 & $(0.2)$ & 5.4 & $(0.3)$ & $<0.001$ \\
\hline Relative neutrophils, $\%$ & 57 & $(2)$ & 63 & (2) & 0.05 \\
\hline
\end{tabular}

*To account for repeated measurements, mean (SEM) levels were calculated using mixed models after adjusting for centred age. 
Table 3 Mean effects $(95 \% \mathrm{Cl})^{*}$ of welding fume exposure on baseline to 6 hours postbaseline changes in levels of systemic inflammatory markers

\begin{tabular}{|c|c|c|c|c|}
\hline \multirow[b]{2}{*}{$\begin{array}{l}\text { C-reactive protein, } \mathrm{mg} / \mathrm{l} \\
\text { Fibrinogen, } \mathrm{mg} / \mathrm{dl} \\
\text { White blood cells, } \times 10^{3} / \mu \mathrm{l} \\
\text { Absolute neutrophils, } \times 10^{3} / \mu \mathrm{l} \\
\text { Relative neutrophils, } \%\end{array}$} & \multicolumn{2}{|c|}{ Crude model } & \multicolumn{2}{|c|}{ Adjusted model } \\
\hline & $\begin{array}{l}0.24 \\
-24 \S \\
0.5 \S \\
0.6 \ddagger \\
3 \S\end{array}$ & $\begin{array}{l}(-0.08 \text { to } 0.56) \\
(-48 \text { to } 1) \\
(-0.1 \text { to } 1.1) \\
(0.01 \text { to } 1.1) \\
(-0.3 \text { to } 7)\end{array}$ & $\begin{array}{l}0.17 \\
-24 \S \\
0.6 \ddagger \\
0.7 \ddagger \\
4 \S\end{array}$ & $\begin{array}{l}(-0.17 \text { to } 0.51) \\
(-51 \text { to } 3) \\
(0 \text { to } 1.3) \\
(0.1 \text { to } 1.3) \\
(-0.2 \text { to } 8)\end{array}$ \\
\hline & \multicolumn{4}{|c|}{ Adjusted modelt with interaction term for smoking status } \\
\hline & \multicolumn{2}{|c|}{ Non-smokers } & \multicolumn{2}{|c|}{ Smokers } \\
\hline $\begin{array}{l}\text { C-reactive protein, } \mathrm{mg} / \mathrm{l} \\
\text { Fibrinogen, } \mathrm{mg} / \mathrm{dl} \\
\text { White blood cells, } \times 10^{3} / \mu \mathrm{l} \\
\text { Absolute neutrophils, } \times 10^{3} / \mu \mathrm{l} \\
\text { Relative neutrophils, } \%\end{array}$ & $\begin{array}{l}0.17 \\
-32 \ddagger \\
0.8 \ddagger \\
1.0 \ddagger \\
6 \ddagger\end{array}$ & $\begin{array}{l}(-0.22 \text { to } 0.56) \\
(-63 \text { to }-1) \\
(0.1 \text { to } 1.6) \\
(0.4 \text { to } 1.7) \\
(1 \text { to } 10)\end{array}$ & $\begin{array}{l}0.20 \\
8 \\
0.01 \\
-0.4 \\
-3\end{array}$ & $\begin{array}{l}(-0.60 \text { to } 1.00) \\
(-55 \text { to } 70) \\
(-1.5 \text { to } 1.5) \\
(-1.7 \text { to } 0.9) \\
(-12 \text { to } 6)\end{array}$ \\
\hline
\end{tabular}

${ }^{*}$ To account for repeated measurements, mean $(95 \% \mathrm{Cl})$ changes across the workday were calculated using mixed models.

†Models adjusted for centred age and smoking status. $\neq \mathrm{p}<0.05 ; \S \mathrm{p}<0.10$.

significantly the association between $\mathrm{PM}_{2.5}$ concentrations and CRP levels $(\mathrm{p}=0.6)$.

\section{DISCUSSION}

Welding fume is comprised of various gases and metal containing fine and ultrafine particles, with $90 \%$ of the particles having an aerodynamic mass median diameter less than $1 \mu \mathrm{m} .{ }^{12}$ In the present study, the median $\mathrm{PM}_{2.5}$ concentration for welders was $1.69 \mathrm{mg} / \mathrm{m}^{3}$, which was significantly greater than that for controls, $0.04 \mathrm{mg} / \mathrm{m}^{3}$ ( $\left.p<0.001\right)$. We found that acute exposure to welding fume was associated with increased levels of systemic inflammatory markers. Additionally, smoking was found to modify the effect of welding fume on specific inflammatory markers. Immediately following welding fume exposure, non-smokers experienced a significant increase in circulating WBC counts, specifically absolute and relative neutrophil counts, and a significant decrease in fibrinogen levels. Sixteen hours after exposure, both non-smokers and smokers experienced significantly increased levels of CRP. Significant PM $_{2.5}$ exposureresponse relations confirmed the welding fume associated increase in absolute neutrophil counts in non-smokers and CRP levels in all subjects.

In non-smokers, welding fume exposure was associated with a mean increase in WBC count by $0.8 \times 10^{3} / \mu \mathrm{l}(95 \% \mathrm{CI}$ 0.1 to 1.6 ), a $13 \%$ increase from baseline. Likewise, neutrophil counts in non-smokers increased by $1.0 \times 10^{3} / \mu \mathrm{l}(95 \%$ CI 0.4 to 1.7 ), indicating that the increase in WBC counts following exposure may be mostly attributable to increased neutrophil counts. A significant exposure-response association also was observed between $\mathrm{PM}_{2.5}$ exposure and neutrophil counts in non-smokers $(p=0.04)$. There was no significant change in
WBC and neutrophil counts following welding fume exposure in smokers $(p \geqslant 0.6)$. In smokers, the acute inflammatory response as assessed by change in peripheral WBC counts was not significant, probably due to the fact that smokers already had an increased mean baseline WBC count of $8.5 \times 10^{3} / \mu \mathrm{l}$ (SD 0.4$)$, which was $1.7 \times 10^{3} / \mu \mathrm{l}(95 \%$ CI 0.9 to 2.4) higher compared to non-smokers. Similarly, smokers had significantly higher neutrophil counts compared to nonsmokers $(\mathrm{p}<0.001)$. In previous studies, current smokers have been found to have increased WBC counts compared to former or never-smokers. ${ }^{25}{ }^{26}$ One concern regarding the lack of change seen in smokers is that some of the subjects performed boilermaking work the day before participating in the study. The residual inflammation from the previous day's work, in addition to the inflammatory response from smoking, may have contributed to the inability to observe a significant change in WBC counts in response to welding fume exposure.

Other studies also have shown that exposure to ambient and occupational particulate matter is associated with increased WBC and neutrophil counts. ${ }^{22}$ A study by Schwartz examined the association between urban air exposure and various blood markers. ${ }^{22}$ Schwartz observed a significant positive relation between circulating WBC counts and particulate matter with an aerodynamic mass median diameter $\leqslant 10 \mu \mathrm{m} \quad\left(\mathrm{PM}_{10}\right)$, after controlling for several variables including smoking. ${ }^{22}$ The mean $\mathrm{PM}_{10}$ exposure in the Schwartz study was $35.2 \mu \mathrm{g} / \mathrm{m}^{3}$, nearly 50 -fold less than the mean $\mathrm{PM}_{2.5}$ exposure in the welders in our study. In another study, non-smoking subjects exposed to diesel exhaust for one hour at a $\mathrm{PM}_{10}$ concentration of $300 \mu \mathrm{g} / \mathrm{m}^{3}$, experienced increases in peripheral neutrophil counts six hours after exposure. ${ }^{29}$

Table 4 Mean effects $(95 \% \mathrm{Cl})^{*}$ of welding fume exposure on baseline to 24 hours postbaseline changes in levels of systemic inflammatory markers

\begin{tabular}{lllll}
\hline & \multicolumn{2}{l}{ Crude model } & \multicolumn{2}{l}{ Adjusted modelt } \\
\hline C-reactive protein, $\mathrm{mg} / \mathrm{l}$ & $0.95 \ddagger$ & $(0.23$ to 1.67$)$ & $0.90 \ddagger$ & $(0.17$ to 1.64$)$ \\
Fibrinogen, $\mathrm{mg} / \mathrm{dl}$ & -21 & $(-60$ to 17$)$ & -22 & $(-63$ to 18$)$ \\
White blood cells, $\times 10^{3} / \mu \mathrm{l}$ & 0.5 & $(-1.0$ to 2.0$)$ & 0.5 & $(-1.0$ to 2.0$)$ \\
Absolute neutrophils, $\times 10^{3} / \mu \mathrm{l}$ & 0.7 & $(-0.7$ to 2.1$)$ & 0.7 & $(-0.7$ to 2.2$)$ \\
Relative neutrophils, \% & 2 & $(-7$ to 11$)$ & 2 & $(-8$ to 11$)$ \\
\hline
\end{tabular}

${ }^{*}$ To account for repeated measurements, mean $(95 \% \mathrm{Cl})$ changes across the workday were calculated using mixed models.

†Models adjusted for centred age and smoking status. $\neq \mathrm{p}<0.05$. 
Table 5 Mean effects $(95 \% \mathrm{Cl})^{*}$ of $\mathrm{PM}_{2.5}$ exposure on baseline to 6 hours post-baseline changes in levels of systemic inflammatory markers

\begin{tabular}{|c|c|c|c|c|}
\hline \multirow[b]{2}{*}{$\begin{array}{l}\text { C-reactive protein, } \mathrm{mg} / \mathrm{l} \\
\text { Fibrinogen, } \mathrm{mg} / \mathrm{dl} \\
\text { White blood cells, } \times 10^{3} / \mu \mathrm{l} \\
\text { Absolute neutrophils, } \times 10^{3} / \mu \mathrm{l} \\
\text { Relative neutrophils, \% }\end{array}$} & \multicolumn{2}{|c|}{ Crude model } & \multicolumn{2}{|c|}{ Adjusted model $†$} \\
\hline & $\begin{array}{l}0.08 \\
-7 \\
0.2 \\
0.1 \\
0.3\end{array}$ & $\begin{array}{l}(-0.05 \text { to } 0.22) \\
(-18 \text { to } 3) \\
(-0.1 \text { to } 0.5) \\
(-0.1 \text { to } 0.4) \\
(-1 \text { to } 2)\end{array}$ & $\begin{array}{l}0.06 \\
-7 \\
0.2 \\
0.2 \\
0.2\end{array}$ & $\begin{array}{l}(-0.07 \text { to } 0.20) \\
(-19 \text { to } 4) \\
(-0.1 \text { to } 0.5) \\
(-0.1 \text { to } 0.4) \\
(-2 \text { to } 2)\end{array}$ \\
\hline & \multicolumn{4}{|c|}{ Adjusted model† with interaction term for smoking status } \\
\hline & \multicolumn{2}{|c|}{ Non-smokers } & \multicolumn{2}{|c|}{ Smokers } \\
\hline $\begin{array}{l}\text { C-reactive protein, } \mathrm{mg} / \mathrm{l} \\
\text { Fibrinogen, } \mathrm{mg} / \mathrm{dl} \\
\text { White blood cells, } \times 10^{3} / \mu \mathrm{l} \\
\text { Absolute neutrophils, } \times 10^{3} / \mu \mathrm{l} \\
\text { Relative neutrophils, } \%\end{array}$ & $\begin{array}{l}0.14 \\
-10 \\
0.3 \S \\
0.3 \ddagger \\
1\end{array}$ & $\begin{array}{l}(-0.03 \text { to } 0.31) \\
(-24 \text { to } 5) \\
(-0.05 \text { to } 0.7) \\
(0.02 \text { to } 0.6) \\
(-1 \text { to } 4)\end{array}$ & $\begin{array}{l}-0.06 \\
-3 \\
0.1 \\
-0.1 \\
-2\end{array}$ & $\begin{array}{l}(-0.28 \text { to } 0.17) \\
(-22 \text { to } 16) \\
(-0.4 \text { to } 0.5) \\
(-0.5 \text { to } 0.3) \\
(-5 \text { to } 1)\end{array}$ \\
\hline \multicolumn{5}{|c|}{$\begin{array}{l}\text { *The coefficient is expressed as the change in the systemic inflammatory marker per } 1 \mathrm{mg} / \mathrm{m}^{3} \text { incremental change } \\
\text { in } \mathrm{PM}_{2.5} \text { concentration. } \\
\dagger \text { Models adjusted for centred age and smoking status. } \\
\mp p<0.05 ; \S p<0.10 \text {. }\end{array}$} \\
\hline
\end{tabular}

In blood samples taken 16 hours after exposure to welding fume, WBC and neutrophil counts in non-smokers were not found to be significantly increased compared to baseline levels. However, the similar effect estimates obtained from both the 6 hours and 24 hours post-baseline models indicated that acute systemic inflammation caused by welding fume exposure persisted. Each $1 \mathrm{mg} / \mathrm{m}^{3}$ increase in $\mathrm{PM}_{2.5}$ concentration was associated with a $0.3 \times 10^{3} / \mu$ l increase in absolute neutrophil counts immediately after exposure compared to a $0.2 \times 10^{3} / \mu \mathrm{l}$ increase 16 hours post-exposure in non-smokers.

In addition to WBC counts, CRP and fibrinogen levels also were investigated in our study. Epidemiological studies have found that CRP and fibrinogen levels are increased in cigarette smokers. ${ }^{24}{ }^{25}$ In our study, the baseline CRP and fibrinogen levels were not significantly different in nonsmokers and smokers $(p>0.2)$. Unlike the other studies which had 4000+ subjects each, this study had a small number of subjects $(\mathrm{n}=37)$ and most likely did not have adequate power to detect subtle differences in baseline levels. After exposure to welding fume, we observed a significant decrease in fibrinogen levels in non-smokers $(p=0.04)$; however, a significant exposure-response relation between fibrinogen levels and $\mathrm{PM}_{2.5}$ exposure was not found $(p=0.2)$. No significant change in fibrinogen levels was observed in smokers following welding exposure $(p=0.8)$. Epidemiological studies examining the relation between fibrinogen levels and particle exposure have observed conflicting results. Seaton and colleagues found that ambient $\mathrm{PM}_{10}$ measurements (range $16 \mu \mathrm{g} / \mathrm{m}^{3}$ to $24 \mu \mathrm{g} / \mathrm{m}^{3}$ ) were negatively associated with fibrinogen levels in non-smokers. ${ }^{23}$ However, Schwartz found that $\mathrm{PM}_{10}$ exposure was significantly associated with increased fibrinogen, ${ }^{22}$ while Sørensen and colleagues did not observe a significant association between ambient $\mathrm{PM}_{2.5}$ exposure (mean $\mathrm{PM}_{2.5}$ concentration of $16.1 \mu \mathrm{g} / \mathrm{m}^{3}$ ) and fibrinogen levels. ${ }^{30}$ Due to the circadian variation of fibrinogen, using this marker to detect changes associated with exposure may be difficult. ${ }^{31}{ }^{32}$

Our study found that welding fume was not associated with significant changes in CRP levels immediately following exposure. However, 16 hours after exposure, a significant increase in CRP levels was observed in both non-smokers and smokers $(p=0.02)$. Smoking status was not found to significantly affect the association between $\mathrm{PM}_{2.5}$ exposure and CRP levels $(p=0.6)$. CRP levels increased by $0.90 \mathrm{mg} / \mathrm{l}$ (95\% CI 0.17 to 1.64 ), resulting in a $39 \%$ increase from baseline. The exposure-response relation between the previous day's $\mathrm{PM}_{2.5}$ concentrations and CRP levels was also statistically significant $(p=0.001)$. Each $1 \mathrm{mg} / \mathrm{m}^{3}$ increase in $\mathrm{PM}_{2.5}$ exposure on the previous day was associated with a $0.78 \mathrm{mg} / \mathrm{l}$ (95\% CI 0.35 to 1.22 ) increase in CRP levels.

Studies investigating the effect of particulate air pollution on systemic inflammatory markers found that increased exposure to particulate matter was associated with significantly increased levels of CRP. ${ }^{21} 2333$ Peters and colleagues observed that particle exposure (mean total suspended particle concentration of $54.0 \mu \mathrm{g} / \mathrm{m}^{3}$ ) was positively associated with CRP levels on the same day. ${ }^{21}$ However, the Peters study also indicated that particle exposure from the previous day was found to have a stronger effect on CRP levels, as shown in our study. ${ }^{21} \mathrm{~A}$ recent study by Pope and colleagues also found a significant exposure-response association between $\mathrm{PM}_{2.5}$ concentrations (mean $23.7 \mu \mathrm{g} / \mathrm{m}^{3}$ ) and CRP levels. ${ }^{33}$ In a study by Seaton and colleagues, a positive association was found between city centre $\mathrm{PM}_{10}$ measurements over a three day period and CRP levels. ${ }^{23}$

Table 6 Mean effects $(95 \% \mathrm{Cl})^{*}$ of $\mathrm{PM}_{2.5}$ exposure on baseline to 24 hours post-baseline changes in levels of systemic inflammatory markers

\begin{tabular}{lllll}
\hline & \multicolumn{2}{l}{ Crude model } & \multicolumn{2}{l}{ Adjusted model $\dagger$} \\
\hline C-reactive protein, $\mathrm{mg} / \mathrm{l}$ & $0.78 \ddagger$ & $(0.35$ to 1.21$)$ & $0.78 \ddagger$ & $(0.35$ to 1.22$)$ \\
Fibrinogen, $\mathrm{mg} / \mathrm{dl}$ & -3 & $(-25$ to 20$)$ & -2 & $(-25$ to 21$)$ \\
White blood cells, $\times 10^{3} / \mu \mathrm{l}$ & 0.2 & $(-0.7$ to 1.2$)$ & 0.2 & $(-0.7$ to 1.2$)$ \\
Absolute neutrophils, $\times 10^{3} / \mu \mathrm{l}$ & 0.2 & $(-0.7$ to 1.2$)$ & 0.2 & $(-0.8$ to 1.1$)$ \\
Relative neutrophils, \% & 0.2 & $(-6$ to 6$)$ & -0.2 & $(-6$ to 6$)$ \\
\hline
\end{tabular}

*The coefficient is expressed as the change in the systemic inflammatory marker per $1 \mathrm{mg} / \mathrm{m}^{3}$ incremental change in $\mathrm{PM}_{2.5}$ concentration from the previous day.

†Models adjusted for centred age and smoking status. $\neq \mathrm{p}<0.05$. 
Many studies have shown that increased levels of systemic inflammatory markers are associated with increased risk of coronary heart disease and also predict adverse cardiovascular outcomes, although the exact mechanisms remain unclear. ${ }^{14} 15^{17}{ }^{18}$ Chronic inflammation plays a major role in the pathogenesis of coronary heart disease. ${ }^{34} 35$ Increased levels of CRP may contribute directly to the atherogenic process or may reflect simply the extent of inflammation associated with atherosclerosis. ${ }^{18}$ Acute systemic inflammation also is associated with a series of adverse responses, including plaque rupture and platelet aggregation, that eventually lead to acute cardiac events. ${ }^{36}$ Even if these inflammatory markers are not involved directly in the aetiology of coronary heart disease, their usefulness as an early indicator of potential disease is of clinical value.

In conclusion, we observed acute systemic inflammatory responses following occupational exposures to high levels of fine particulate matter in a cohort of welders without overt cardiovascular diseases. An immediate increase was observed in peripheral WBC counts, mainly the neutrophils, but the acute effect on WBC was noted among non-smokers only. Sixteen hours after welding exposure, we began to observe a significant increase in CRP, among both smokers and nonsmokers. The clinical significance of acute changes in WBC and CRP levels associated with welding fume exposure needs to be investigated further.

\section{ACKNOWLEDGEMENTS}

The authors are grateful to L Ngo, E Rodrigues, S Mukherjee, S Magari, J Cavallari, J Hart, L Su, Z Wei, and J Natkin for their assistance. Special thanks goes to the staff and members of the International Brotherhood of Boilermakers, Iron Ship Builders, Blacksmiths, Forgers and Helpers of Local No. 29, Quincy, Massachusetts.

\section{Authors' affiliations}

J Y Kim, J-C Chen, D C Christiani, Department of Environmental Health, Occupational Health Program, Harvard School of Public Health, Boston, MA 02115, USA

P D Boyce, Pulmonary and Critical Care Unit, Department of Medicine, Massachusetts General Hospital, Harvard Medical School, Boston, MA 02114 , USA

This study was supported by NIH grants ES09860, ES00002, and CA94715. Dr Kim was supported by Harvard-NIOSH Education and Research Center training grant T42110421 and a NIEHS post-doctoral fellowship T32 ES07069.

\section{REFERENCES}

1 Burgess WA. Recognition of health hazards in industry. A review of materials and processes. New York: John Wiley and Sons, Inc, 1995.

2 Glinsmann PW, Rosenthal FS. Evaluation of an aerosol photometer for monitoring welding fume levels in a shipyard. Am Ind Hyg Assoc J 1985:46:391-5.

3 El-Zein M, Malo JL, Infante-Rivard C, et al. Prevalence and association of welding related systemic and respiratory symptoms in welders. Occup Environ Med 2003;60:655-61.

4 Mueller EJ, Seger DL. Metal fume fever-a review. J Emerg Med 1985;2:271-4.

5 Beckett WS, Pace PE, Sferlazza SJ, et al. Airway reactivity in welders: a controlled prospective cohort study. J Occup Environ Med 1996;38:1229-38. 6 Bradshaw LM, Fishwick D, Slater T, et al. Chronic bronchitis, work related respiratory symptoms, and pulmonary function in welders in New Zealand. Occup Environ Med 1998:55:150-4.

7 El-Zein M, Malo JL, Infante-Rivard C, et al. Incidence of probable occupational asthma and changes in airway calibre and responsiveness in apprentice welders. Eur Respir J 2003;22:513-18.
8 Özdemir O, Numanoğlu N, Gönüllü U, et al. Chronic effects of welding exposure on pulmonary function tests and respiratory symptoms. Occup Environ Med 1995;52:800-3.

9 Wang ZP, Larsson K, Malmberg P, et al. Asthma, lung function, and bronchial responsiveness in welders. Am J Ind Med 1994;26:741-54.

10 Erkinjuntti-Pekkanen R, Slater T, Cheng $S$, et al. Two year follow up of pulmonary function values among welders in New Zealand. Occup Environ Med 1999:56:328-33.

11 Moulin JJ, Wild P, Haguenoer JM, et al. A mortality study among mild steel and stainless steel welders. Br J Ind Med 1993;50:234-43.

12 Newhouse ML, Oakes D, Woolley AJ. Mortality of welders and other craftsmen at a shipyard in NE England. Br J Ind Med 1985;42:406-10.

13 Siögren B, Fossum T, Lindh $T$, et al. Welding and ischemic heart disease. Int J Occup Environ Health 2002;8:309-11.

14 Brown DW, Giles WH, Croft JB. White blood cell count: an independent predictor of coronary heart disease mortality among a national cohort. J Clin Epidemiol 2001;54:316-22.

15 Danesh J, Collins R, Appleby P, et al. Association of fibrinogen, C-reactive protein, albumin, or leukocyte count with coronary heart disease: metaanalyses of prospective studies. JAMA 1998;279:1477-82.

16 Eriksson M, Egberg N, Wamala S, et al. Relationship between plasma fibrinogen and coronary heart disease in women. Arterioscler Thromb Vasc Biol 1999; 19:67-72.

17 Folsom AR, Aleksic N, Catellier D, et al. C-reactive protein and incident coronary heart disease in the Atherosclerosis Risk In Communities (ARIC) study. Am Heart J 2002;144:233-8.

18 Koenig W, Sund M, Fröhlich M, et al. C-Reactive protein, a sensitive marker of inflammation, predicts future risk of coronary heart disease in initially healthy middle-aged men: results from the MONICA (Monitoring Trends and Determinants in Cardiovascular Disease) Augsburg Cohort Study, 1984 to 1992. Circulation 1999;99:237-42.

19 Andreotti F, Burzotta F, Maseri A. Fibrinogen as a marker of inflammation: a clinical view. Blood Coagul Fibrinolysis 1999;10(suppl 1):S3-4.

20 Pepys MB, Hirschfield GM. C-reactive protein: a critical update. J Clin Invest 2003;111:1805-12.

21 Peters A, Fröhlich $M$, Döring $A$, et al. Particulate air pollution is associated with an acute phase response in men; results from the MONICA-Augsburg Study. Eur Heart J 2001;22:1 198-204.

22 Schwartz J. Air pollution and blood markers of cardiovascular risk. Environ Health Perspect 2001;109(suppl 3):405-9.

23 Seaton A, Soutar A, Crawford V, et al. Particulate air pollution and the blood. Thorax 1999:54:1027-32.

24 Bazzano LA, He J, Muntner P, et al. Relationship between cigarette smoking and novel risk factors for cardiovascular disease in the United States. Ann Intern Med 2003; 138:891-7.

25 Fröhlich $M$, Sund $M$, Löwel $H$, et al. Independent association of various smoking characteristics with markers of systemic inflammation in men. Results from a representative sample of the general population (MONICA Augsburg Survey 1994/95). Eur Heart J 2003;24:1365-72.

26 Smith MR, Kinmonth AL, Luben RN, et al. Smoking status and differential white cell count in men and women in the EPIC-Norfolk population. Atherosclerosis 2003;169:331-7.

27 Clauss A. Gerinnungsphysiologische schnellmethode zur bestimmung des fibrinogens [Rapid physiological coagulation method in determination of fibrinogen]. Acta Haematol 1957;17:237-46.

28 Verbeke G, Molenberghs G. Linear mixed models in practice: A SAS-oriented approach. New York: Springer, 1997.

29 Salvi S, Blomberg A, Rudell B, et al. Acute inflammatory responses in the airways and peripheral blood after short-term exposure to diesel exhaust in healthy human volunteers. Am J Respir Crit Care Med 1999;159:702-9.

30 Sørensen $M$, Daneshvar B, Hansen $M$, et al. Personal PM 2.5 exposure and markers of oxidative stress in blood. Environ Health Perspect 2003;111:161-6.

31 Bremner WF, Sothern RB, Kanabrocki EL, et al. Relation between circadian patterns in levels of circulating lipoprotein(a), fibrinogen, platelets, and related lipid variables in men. Am Heart J 2000;139:164-73.

32 Pasqualetti $P$, Festuccia V, Acitelli $P$, et al. Circadian rhythms of fibrinogen antithrombin III and plasminogen in chronic liver diseases of increasing severity. Haemostasis 1997;27:140-8.

33 Pope CA 3rd, Hansen ML, Long RW, et al. mbient particulate air pollution, heart rate variability, and blood markers of inflammation in a panel of elderly subjects. Environ Health Perspect 2004;1 12:339-45.

34 Ross R. Atherosclerosis - an inflammatory disease. N Engl J Med 1999;340:115-26.

35 Plutzky J. Inflammatory pathways in atherosclerosis and acute coronary syndromes. Am J Cardiol 2001;88:10K-15K.

36 Lind L. Circulating markers of inflammation and atherosclerosis. Atherosclerosis 2003;169:203-14.

37 Tousoulis D, Davies G, Stefanadis C, et al. Inflammatory and thrombotic mechanisms in coronary atherosclerosis. Heart 2003;89:993-7. 